\title{
Noise Levels in Two Emergency Departments Before and After the Introduction of Electronic Whiteboards
}

\author{
Morten Hertzum*
}

Computer Science and Informatics, Roskilde University, Universitetsvej 1, Bldg 43.2, DK-4000 Roskilde, Denmark

\begin{abstract}
Purpose: Hospital work generates noise. This article investigates the noise level in emergency departments (EDs) to assess the need to address this aspect of the work environment and to investigate whether the replacement of dryerase with electronic whiteboards lowers the noise level.

Method: In Study I we measured the noise level at the three coordination centers of an ED while it was still using dryerase whiteboards and after it had switched to electronic whiteboards. In Study II we made similar noise measurements at another ED, supplemented with observation.

Results: The median daily equivalent continuous noise levels were 60.0, 55.3, and $55.4 \mathrm{~dB}(\mathrm{~A})$ at the three coordination centers in Study I and $56.5 \mathrm{~dB}(\mathrm{~A})$ at the coordination center in Study II. In both studies the noise levels were higher during workdays than weekends and higher during day and evening shifts than during night shifts. The maximum equivalent continuous noise levels across 1 second were above $80 \mathrm{~dB}(\mathrm{~A})$ at all four coordination centers. At two of the centers above $80 \mathrm{~dB}(\mathrm{~A})$ noises also occurred at night. After the introduction of electronic whiteboards the noise level was lowered at one ED but unchanged at the other ED. The main noise sources at the ED in Study II were clinicians talking, phones ringing, and equipment being moved around.

Conclusion: The noise level at both EDs is above levels previously found to decrease the quality of work, increase the strain on the staff, or both. The transition from dry-erase to electronic whiteboards gave mixed results with respect to alleviating the noise problems.
\end{abstract}

Keywords: Emergency department, noise, stressors, whiteboards, work environment.

\section{INTRODUCTION}

The delivery of patient care in hospitals generates noise [1-3]. Emergency departments (EDs) are no exception and may even be particularly noisy due to the acute nature of patients' complaints, the typically high level of activity, and the considerable number of people simultaneously present. A noisy work environment makes it more difficult to communicate and perform cognitively complex tasks, and generally induces stress $[3,4]$. Thus, accurate knowledge of the noise level in EDs is important in order to assess this strain on the staff as well as the need for interventions to reduce it. This article examines the noise level in two Danish EDs and the effect on the noise level of substituting electronic for dry-erase whiteboards.

We focus on the noise level in the ED clinicians' work and coordination centers, rather than in patient rooms. The noise level in these centers is an important element of the work environment of all ED staff but especially that of the physicians and nurses in the central coordinating roles because they spend most of their shifts in the coordination centers. Prominent noise sources include communication among clinicians, phones ringing, alarms on monitoring equipment, public address systems, movement of beds and

Address correspondence to this author at the Computer Science and Informatics, Roskilde University, Universitetsvej 1, Bldg 43.2, DK-4000 Roskilde, Denmark; Tel: +45 4674 3077; E-mail: mhz@ruc.dk equipment, doors slamming, and patients crying or in pain [5-7]. We measured the combined noise level from all such noise sources in the coordination centers of two Danish EDs. In the first ED (Study I) we investigated the noise levels in the three coordination centers at all shifts and all days of the week. In the second ED (Study II) we made similar measurements to strengthen the generalizability of our findings and we report from observations in the ED to give an impression of the work activities that generate the noise and are performed in its presence. Because the ED whiteboard is recognized as an artifact central to the coordination of ED work $[8,9]$, it may affect the noise level in the coordination centers. In both Study I and Study II, we therefore compared the noise levels during the use of dryerase and electronic whiteboards. The visual layout of both whiteboards consisted of a matrix-like structure with a row of information for each patient, including time of arrival, room, patient name, age, triage level, problem, attending physician, attending nurse, and next action. The information on the electronic whiteboard was however more legible and for several of the fields more detailed than on the dry-erase whiteboard. In addition, the information on the electronic whiteboard could be accessed from all computers in the ED and thus did not require visiting the coordination centers. Electronic ED whiteboards have specifically been found to improve the communication and coordination of care [10], make work more efficient [11], improve ED clinicians' overview of their work and make information available 
where and when needed [12], and may therefore be hypothesized to reduce noise levels by replacing some ephemeral, oral information with permanent, visual information.

In the following we describe related work on the level of noise in EDs. Notably, none of these studies account for the type of artifacts, such as whiteboards, used for coordinating work in the studied EDs. Then, we report from Studies I and II. For both studies the noise measurements comprised a four-week period of noise measurements while the ED was using dry-erase whiteboards and a subsequent four-week period of noise measurements after the ED had shifted to the use of electronic whiteboards. Finally, we discuss the results of our two studies and their implications for EDs.

\section{RELATED WORK}

Noise levels are predominantly measured in A-weighted decibel, denoted $\mathrm{dB}(\mathrm{A})$. The A-weighting approaches the sound perception of the human ear. Noise fluctuates over time, and because the decibel scale is logarithmic noise levels cannot simply be averaged. Instead, the equivalent continuous sound level $\left(L_{e q}\right)$ is defined as the steady sound pressure level that, over a specified period of time, has the same total energy as the actual fluctuating noise [4]. Formally, the equivalent continuous sound level for a time period $(T)$ during which the noise level $\left(L_{n o i s e, i}\right)$ has been measured in the same way $n$ times is:

$$
L_{e q, T}=10 \log _{10}\left(\frac{1}{n} \sum_{i=1}^{n} 10^{L_{n o i s e, ~} / / 10}\right) \quad \text { Equation } 1
$$

If the measurements of the noise level are A-weighted the equivalent continuous sound level is denoted $L_{\text {Aeq }}$.

A noise level of $0 \mathrm{~dB}(\mathrm{~A})$ corresponds to the lower limit of human audibility. In terms of upper levels, the US Environmental Protection Agency [13] recommends daily $L_{\text {Aeq }}$ values below $45 \mathrm{~dB}(\mathrm{~A})$ for hospitals and night-time values below $35 \mathrm{~dB}(\mathrm{~A})$. The World Health Organization [4] recommends daytime and night-time $L_{\text {Aeq }}$ values below 30 $\mathrm{dB}(\mathrm{A})$ for hospitals. The EPA and WHO recommendations refer, however, to background noise, which is the noise in unoccupied buildings and thus excludes the noise of patients and staff. As the main noise sources in hospitals are patients, staff, and their activities [5, 14], these recommendations are difficult to transfer to measurements of the noise level in occupied hospitals. Pope [15] states that "there are no official or standardised guidelines to regulate noise levels in occupied hospitals." For occupied hospital nurseries, Philbin et al. [16] recommend that hourly $L_{\text {Aeq }}$ values do not exceed $50 \mathrm{~dB}(\mathrm{~A})$, that noise levels exceed $55 \mathrm{~dB}(\mathrm{~A})$ at most $10 \%$ of any hour, and that the maximum noise level for periods of one second or more is at most $70 \mathrm{~dB}(\mathrm{~A})$.

Table 1 shows noise levels from previous studies of EDs and, for comparison, other hospital departments. With Tijunelis et al. [7] as an exception, the noise levels in the EDs are generally high. For example, Orellana et al. [17] reported daily equivalent continuous noise levels between 61 and $69 \mathrm{~dB}(\mathrm{~A})$ in seven locations in an American $\mathrm{ED}$ and maximum $L_{\text {Aeq, ls }}$ values above $90 \mathrm{~dB}(\mathrm{~A})$ for most of the seven locations. Vinodhkumaradithyaa et al. [18] reported an hourly equivalent continuous noise level of $71 \mathrm{~dB}(\mathrm{~A})$ at an Indian ED in the morning (09:00-10:00) and $68 \mathrm{~dB}(\mathrm{~A})$ in the evening (18:00-19:00). They also reported minimum noise measurements $\left(L_{\text {Aeq, } 125 \mathrm{~ms}}\right.$ values) of 59 and $62 \mathrm{~dB}(\mathrm{~A})$ during the morning and evening hour, respectively, suggesting either a permanently noisy environment or that measurements were made during busy periods of the day. Of the non-ED studies, Tsara et al. [19] measured the noise level in a Greek intensive care unit for a period of one week. They found hourly equivalent continuous noise levels in the ranges 55-66 $\mathrm{dB}(\mathrm{A})$ for days and evenings and 55-62 $\mathrm{dB}(\mathrm{A})$ for nights. Daytime and night-time noise levels were also compared by MacKenzie and Galbrun [14] and byMcLaren and Maxwell-Armstrong [20], in both studies with quieter nights. It is notable that 8 of the 10 studies in Table $\mathbf{1}$ were based on noise measurements collected over a period of no more than 24 hours. This makes it hard to know how representative the measurements are. It is also notable that 3 of the 6 ED studies appear to report simple averages of noise measurements rather than equivalent continuous noise levels. Simple averages of decibel values are difficult to make sense of and differ from equivalent continuous noise levels calculated for the same noise data.

Noise in healthcare settings has been found to interfere with communication [17], to impair teaching between residents and staff physicians [21], to increase stress and annoyance [22], to increase emotional exhaustion and burnout [23], to disrupt sleep which is pertinent to patients' healing processes [24], to cause patients to perceive greater pain [25], and possibly to lead to an increase in medical errors [26]. The effects of noise have also been studied in office settings, with which ED clinicians' coordination centers have some similarities. The findings of these studies include that noise is perceived as more annoying and harmful when it is experienced as uncontrollable, unnecessary or unpredictable [3], that ringing phones and intelligible speech are more distracting than most other noises [27], that intelligible speech at $48 \mathrm{~dB}(\mathrm{~A})$ deteriorates proofreading more than unintelligible noise at $48 \mathrm{~dB}(\mathrm{~A})$ [28], that exposure to noise at $50 \mathrm{~dB}$ deteriorates the performance of cognitively complex tasks more than a nonoise condition [29], and that an equivalent continuous sound level of 51 compared to $39 \mathrm{~dB}(\mathrm{~A})$ decreases memory for words [30].

\section{STUDY I}

To investigate the noise level in the coordination centers of a Danish ED we measured it once a minute for two periods of four weeks. During the first period of measurements (March 2011) the whiteboards in the ED were dry-erase whiteboards. During the second measurement period (September 2011) the ED had been using electronic whiteboards for four months. The study was approved by the management of the ED and by the healthcare region's department for quality and development.

\subsection{Method}

The study took place at the ED of a medium-size hospital in Region Zealand, one of five healthcare regions in Denmark. The ED consisted of an acute area for the patients at the highest triage levels (i.e., the more severe cases), another acute area for the patients at the lower triage levels, a long-term area for the patients admitted up to 24 hours, and a fast-track area for walk-in patients. In total, the ED had 21 
Table 1. Noise Levels in EDs and Other Hospital Departments

\begin{tabular}{|c|c|c|c|c|c|}
\hline \multirow{2}{*}{ Study } & \multirow{2}{*}{ Country } & \multirow{2}{*}{ Department } & \multirow{2}{*}{ Duration of Measurements } & \multicolumn{2}{|c|}{ Noise Level } \\
\hline & & & & $\mathrm{dB}(\mathrm{A})$ & Time Base \\
\hline Buelow [31] & Arizona, US & $\mathrm{ED}$ & 4 hours & $67-73$ & 4h, daytime \\
\hline Orellana et al. [17] & Maryland, US & ED & 1 day & $61-69$ & $L_{\text {Aeq, } 24 h}$ \\
\hline Short et al. [32] & Australia & ED & 1 day & $\sim 55$ & $L_{\text {Aeq, } 24 h}$ \\
\hline Tijunelis et al. [7] & California, US & ED & 12 hours & 43 & $12 \mathrm{~h}$, daytime \\
\hline Vinodhkumaradithyaa et al. [18] & India & ED & 2 hours & $\begin{array}{l}71 \\
68\end{array}$ & 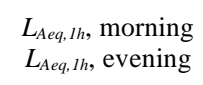 \\
\hline Zun and Downey [33] & Illinois, US & $\mathrm{ED}$ & 205 times & $56-58$ & Not reported \\
\hline MacKenzie and Galbrun [14] & Scotland & ICU & 1 day & $\begin{array}{l}55-58 \\
52-55\end{array}$ & $\begin{array}{c}L_{\text {Aeq, } 24 h} \\
L_{\text {Aeq }, 8 h}, \text { night-time }\end{array}$ \\
\hline Tsara et al. [19] & Greece & ICU & 1 week & $\begin{array}{l}56-66 \\
55-66 \\
55-62\end{array}$ & $\begin{array}{c}L_{\text {Aeq, } 1 h}, \text { day } \\
L_{\text {Aeq, }, 1 h} \text {, evening } \\
L_{\text {Aeq, } 1 h}, \text { night }\end{array}$ \\
\hline McLaren and Maxwell-Armstrong [20] & England & Surgical & 1 day & $\begin{array}{l}59 \\
48\end{array}$ & $\begin{array}{c}L_{\text {Aeq, } 13 h}, \text { daytime } \\
L_{\text {Aeq, } 5 h} \text {, night-time }\end{array}$ \\
\hline Pope [15] & Oregon, US & MSNU & 12 hours & $62-65$ & $L_{\text {Aeq, } 12 h}$, daytime \\
\hline
\end{tabular}

Note: ICU - intensive care unit, MSNU - medical/surgical nursing unit.

patient rooms and was staffed with 120 nurses and 13 fulltime physicians. Besides the full-time physicians, the ED also allocated physicians from other departments on an oncall basis.

The noise measurements targeted the three main coordination centers used by the clinicians for coordinating ED work, preparing to see patients, consulting with their colleagues, writing patient records, and having the timeouts during which the clinicians convened to walk through the patients currently admitted. Each center coordinated one ED area. Center 1 (an office with workplaces for about 6 staff) coordinated the acute area for the patients at the lower triage levels; Center 2 (an open area in the hallway with workplaces for 3-4 staff) coordinated the acute area for the patients at the highest triage levels; and Center 3 (an office with workplaces for up to 10 staff) coordinated the long-term area. In each center a dry-erase whiteboard (first measurement period) or electronic whiteboard (second measurement period) provided an overview of the patients. The visual layout of the dry-erase and electronic whiteboards was similar, and it resembled that of ED whiteboards in most other studies [34].

In the three centers the sound pressure levels were measured with sound level meters from Elma, model 1352C, which complied with the IEC 61672 class 2 standard [35]. The meters were mounted on a wall in each coordination center, slightly less than 2 meters above floor level and in the same place during the two measurement periods. The meters were set to A-weighting and to measure the sound pressure level over a period of one second (the 'slow' setting). That is, each measurement gives a $L_{\text {Aeq, ls }}$ value. These settings are recommended for measuring how humans are affected by non-burst noise [16]. The meters were also set to make a measurement every minute throughout the day. With 3 $($ sound level meters $) \times 2$ (measurement periods $) \times 4$ (weeks) $\times 7 \times 24 \times 60$ (minutes a week) we should obtain a total of 241920 noise measurements. Because the meters could only store about ten days of measurements, the stored measurements had to be transferred to a computer periodically. This downtime resulted in $440(0.18 \%)$ missing measurements. Consequently, we had $241480 L_{\text {Aeq, ls }}$ values for analysis.

For the analysis we calculated $L_{A e q, 24 h}$ values for each day of measurements and $L_{\text {Aeq, } 8 h}$ values for each shift, using Equation 1. See Fig. (1) for an illustration. The statistical analysis consisted of analyses of variance with center (1, 2, 3), day (workday, weekend), whiteboard (dry-erase, electronic), and shift (day, evening, night) as independent variables and the equivalent continuous noise level as the dependent variable. We chose analysis of variance of the equivalent continuous noise levels because it was consistent with previous studies [e.g., 15, 20] and because Rosenthal and Rosnow [36] report that analysis of variance is fairly effective even when the assumption of normal distributions is not met. As a safeguard we also performed the statistical analysis after submitting the $L_{A e q}$ values to an anti-log transformation $\left(10^{\text {LAeq/10 }}\right)$. All significant results reported in the following were also significant in this alternative analysis. Statistical significance was in all analyses set at the level of 0.05 .

In addition to the noise measurements we obtained data about the number of patients seen by the ED during the two measurement periods. The data about this control variable were extracted from the ED's electronic patient record.

\subsection{Results}

A total of 3435 and 3567 patients were treated at the ED during the first and second measurement period, respectively. Thus, the patient load during the two measurement periods was similar. The number of patients 

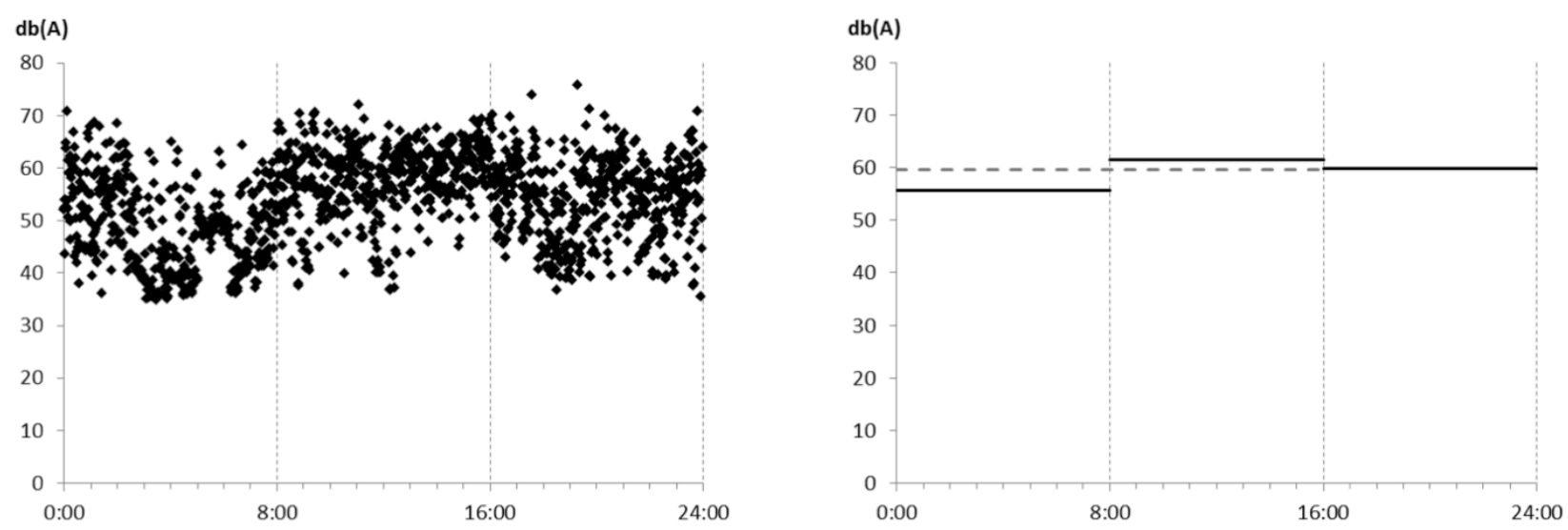

Fig. (1). The noise measurements from Tuesday, September 27, at Center 1. Left: the $1440 L_{\text {Aeq, ls }}$ measurements. Right: the corresponding $L_{\text {Aeq, } 8 h}$ values for the night, day, and evening shifts (solid lines) and the $L_{\text {Aeq,24h }}$ value for the full 24-hour period (dashed line).

during each measurement period also resembled the average monthly number of patients at the ED. The number of ED staff was the same during the two measurement periods.

Table 2 shows the daily equivalent continuous noise levels (i.e., $L_{\text {Aeq,24h }}$ ) at Centers 1,2 , and 3 for workdays and weekends, for days using dry-erase and electronic whiteboards, and in total. For each of the centers the table gives the median $L_{\text {Aeq,24h }}$ value (of the 40 workdays, 16 weekend days, 28 days of using the dry-erase whiteboard, 28 days of using the electronic whiteboard, and 56 total days of measurements). To indicate the spread in the noise levels the table also gives the $L_{\text {Aeq, } 24 h}$ value that was exceeded by $90 \%$ of the daily equivalent continuous noise levels $\left(L_{90}\right)$ and the $L_{\text {Aeq,24h }}$ value that was exceeded by $10 \%$ of the daily equivalent continuous noise levels $\left(L_{10}\right)$.

The medians of the daily equivalent continuous noise levels at Centers 1, 2, and 3 were 60.0, 55.3, and 55.4 $\mathrm{dB}(\mathrm{A})$, respectively. There was a significant effect of center, $F(2$, $165)=193.02, p<0.001$, with Bonferroni-adjusted pairwise comparisons indicating a higher noise level at Center 1 than at Centers 2 and 3. We also found a significant effect of day, $F(1,166)=22.62, p<0.001$, with higher noise levels for workdays than weekend days and a significant effect of whiteboard, $F(1,166)=4.10, p<0.05$, with higher noise levels for days using the dry-erase than electronic whiteboard. The size of both these effects was however small. None of the interactions among center, day, and whiteboard were significant (all $p \mathrm{~s}>0.1$ ).

Table 3 shows the equivalent continuous noise levels for each 8-hour shift (i.e., $L_{A e q, 8 h}$ ). The median day-shift noise levels at Centers 1, 2, and 3 were 61.6, 56.7, and $56.8 \mathrm{~dB}(\mathrm{~A})$, respectively. We found a significant effect of shift, $F(1,502)$ $=312.19, p<0.001$, with Bonferroni-adjusted pairwise comparisons indicating a higher noise level for day than evening shifts and, in turn, a higher noise level for evening than night shifts. A significant interaction between center and shift, $F(4,499)=9.24, p<0.001$, indicated that the lower noise levels for night shifts were mainly due to Centers 1 and 2 . Like for the daily equivalent continuous noise levels we also found a significant effect of center for the 8-hour equivalent continuous noise levels, $F(2,501)=$ $319.12, p<0.001$. Bonferroni-adjusted pairwise comparisons showed a higher noise level at Center 1 than Center 3 and, in turn, a higher noise level at Center 3 than Center 2.

Table 4 shows the range of noise measurements for day, evening, and night shifts in terms of the minimum and maximum equivalent continuous noise levels measured across 1 second. The minimum $L_{\text {Aeq, Is }}$ values were between 28.3 and $33.6 \mathrm{~dB}(\mathrm{~A})$ with the lower values for night shifts and the higher values for Center 2 . For all three centers the maximum day-shift $L_{A e q, 1 s}$ value was above $80 \mathrm{~dB}(\mathrm{~A})$. The maximum $L_{\text {Aeq, ls }}$ values during evening and night shifts were also above $80 \mathrm{~dB}(\mathrm{~A})$ for Centers 1 and 3 but slightly below for Center 2. To describe the higher noise levels further the table also gives the $L_{\text {Aeq, ls }}$ value that was exceeded by $5 \%$ of the 1 -second equivalent continuous noise levels $\left(L_{05}\right)$. Center 1 had the highest $L_{05}$ level with $5 \%$ of the $L_{\text {Aeq, ls }}$ values exceeding $66.4 \mathrm{~dB}(\mathrm{~A})$. That is, during the two four-week measurement periods there were 4025 noise measurements above $66.4 \mathrm{~dB}(\mathrm{~A})$. Except night shifts at Center 2, the top $5 \%$ of the noise measurements were above $60 \mathrm{~dB}(\mathrm{~A})$ for all three centers and all three shifts.

\subsection{Discussion}

With median $L_{\text {Aeq,24h }}$ values between 55.3 and 60.0 for the three coordination centers, the noise level in the ED was high but not as high as that in some other EDs (cf. Table 1). The noise level must be assumed to affect the clinicians' performance negatively because noise levels above $50 \mathrm{~dB}(\mathrm{~A})$ have been found to decrease the performance of cognitive tasks [28-30]. In addition, normal human speech is about 50 $\mathrm{dB}(\mathrm{A})$ and requires a signal-to-noise ratio of $15 \mathrm{~dB}(\mathrm{~A})$ to be fully intelligible [4]. Thus, communication in the ED was either not fully intelligible or the clinicians had to raise their voices to communicate. The maximum $L_{A e q, 1 s}$ values were above $80 \mathrm{~dB}(\mathrm{~A})$ in all three centers and thereby clearly exceeded the limit of $70 \mathrm{~dB}(\mathrm{~A})$ recommended by Philbin et al. [16]. In Center 1, the noisiest of the three centers, $5 \%$ of the day-shift $L_{\text {Aeq, Is }}$ values exceeded $67.6 \mathrm{~dB}(\mathrm{~A})$. Thus, for $5 \%$ of a day shift the noise level was close to or in excess of the recommended maximum limit. The noise level in the ED also exceeded the two other recommendations by Philbin et al. [16], but it should be remembered that their recommendations are for hospital nurseries, not EDs. 
Table 2. Equivalent Continuous Noise Levels Across 24 Hours $\left(L_{A e q, 24 h}\right)$ in $\mathrm{dB}(\mathrm{A}), N=168$ Days

\begin{tabular}{|c|c|c|c|c|c|c|c|c|c|}
\hline & \multicolumn{3}{|c|}{ Center 1} & \multicolumn{3}{|c|}{ Center 2} & \multicolumn{3}{|c|}{ Center 3} \\
\hline & $L_{90}$ & Median & $L_{10}$ & $L_{90}$ & Median & $L_{10}$ & $L_{90}$ & Median & $L_{10}$ \\
\hline \multicolumn{10}{|l|}{ Day } \\
\hline Workday & 58.6 & 60.3 & 62.4 & 53.6 & 55.5 & 56.6 & 54.6 & 55.6 & 57.3 \\
\hline Weekend & 54.8 & 59.0 & 61.2 & 53.2 & 54.7 & 55.7 & 53.8 & 55.0 & 56.2 \\
\hline Electronic & 58.0 & 59.2 & 61.0 & 53.2 & 54.9 & 56.9 & 54.5 & 55.4 & 57.0 \\
\hline Total & 57.8 & 60.0 & 62.2 & 53.6 & 55.3 & 56.4 & 54.3 & 55.4 & 57.1 \\
\hline
\end{tabular}

Table 3. Equivalent Continuous Noise Levels Across 8 Hours $\left(L_{A e q, 8 h}\right)$ in $\mathrm{dB}(\mathrm{A}), N=504$ Shifts

\begin{tabular}{|c|c|c|c|c|c|c|c|c|c|}
\hline & \multicolumn{3}{|c|}{ Center 1} & \multicolumn{3}{|c|}{ Center 2} & \multicolumn{3}{|c|}{ Center 3} \\
\hline Day (08-16) & 58.6 & 61.6 & 63.7 & 54.0 & 56.7 & 58.3 & 55.2 & 56.8 & 58.7 \\
\hline Evening (16-00) & 58.1 & 60.4 & 63.3 & 53.9 & 55.7 & 57.4 & 52.1 & 55.7 & 57.5 \\
\hline Total & 54.8 & 59.7 & 63.2 & 49.2 & 55.0 & 57.7 & 51.6 & 55.6 & 58.0 \\
\hline
\end{tabular}

Table 4. Equivalent Continuous Noise Levels Across 1 Second $\left(L_{A e q, 1 s}\right)$ in $\mathrm{dB}(\mathrm{A}), N=241480$ Measurements

\begin{tabular}{|c|c|c|c|c|c|c|c|c|c|}
\hline & \multicolumn{3}{|c|}{ Center 1} & \multicolumn{3}{|c|}{ Center 2} & \multicolumn{3}{|c|}{ Center 3} \\
\hline Day (08-16) & 32.3 & 67.6 & 84.2 & 36.6 & 62.6 & 81.6 & 33.1 & 62.8 & 81.0 \\
\hline Evening (16-00) & 32.1 & 66.8 & 87.6 & 34.6 & 61.5 & 78.7 & 29.8 & 61.5 & 83.5 \\
\hline Total & 31.4 & 66.4 & 87.6 & 33.6 & 61.0 & 81.6 & 28.3 & 61.7 & 83.5 \\
\hline
\end{tabular}

We found higher noise levels for workdays than weekends and higher noise levels for day shifts than evening shifts, which in turn had higher noise levels than night shifts. These findings corroborate previous studies [19, 20,32] and indicate than in general the busier periods in the ED were also the noisier. In addition, the noise level has decreased with the introduction of electronic whiteboards. The decrease is small but encouraging because many EDs are currently in a process of replacing their dry-erase whiteboards with electronic whiteboards. Importantly, the number of patients has not dropped since the introduction of electronic whiteboards and thus cannot explain away the decrease in noise level.

\section{STUDY II}

The aim of Study II was to consolidate the results of Study I by conducting similar noise measurements at another ED and to give an impression of the work activities that both generate the noise and are performed in its presence. The second aim was accomplished through observation of ED work. The study was approved by the management of the ED and by the healthcare region's department for quality and development.

\subsection{Method}

The study took place at the ED of another medium-size hospital in Region Zealand. The ED comprised 10 patient rooms and consisted of an acute area for patients arriving by ambulance or referred to the ED by their general practitioner and a fast-track area for walk-in patients. Patient treatment at this ED was provided by full-time ED staff, which included 25 physicians and 35 nurses. The ED had one coordination center, the control desk, which was the target of the noise measurements. Clinicians used the control desk for receiving acute patients, coordinating ED work, ordering tests, receiving test results, and consulting with their colleagues. 
To some extent the control desk was also used for preparing to see patients and writing patient records but these activities were mainly performed in an adjacent physician work area. The control desk was located in an open area, which connected the two hallways with the patient rooms.

The sound pressure level at the control desk was measured with one of the sound level meters from Study I. The meter was in both measurement periods mounted on the back wall of the control desk, slightly less than 2 meters above floor level, and configured in the same way as in Study I. That is, a measurement, consisting of an $L_{\text {Aeq, ls }}$ value, was made every minute for two periods of four weeks. During the first measurement period (November 2010) the main coordination artifact at the control desk was a dry-erase whiteboard; during the second measurement period (May 2011) it was an electronic whiteboard, which had been in use for four months. The electronic whiteboard introduced at the ED was the same as in Study I. The downtime associated with periodically transferring stored measurements to a computer resulted in $84(0.10 \%)$ missing measurements, leaving $80556 L_{A e q, l_{s}}$ values for analysis. We analyzed the noise measurements in the same way as in Study I. We also obtained data about the number of patients treated in the acute area of the ED during the two measurement periods. These data were extracted from the nursing records and used as a control variable.

In addition to the noise measurements, the author observed the work at the control desk for a total of 60 hours distributed across both measurement periods. For most of the observations the author was seated in between some equipment, at a distance of about four meters from the control desk. From this position the author had a full view of the control desk, including the whiteboard, and could listen in on conversations at the control desk. For the remainder of the observations the author moved around at the ED but never entered patient rooms when they were in use. The observations were documented in written field notes.

\subsection{Results of Measurements}

In the acute area 1104 and 1073 patients were treated during the first and second measurement period, respectively. Thus, the load of acute patients, who give rise to most of the activity at the control desk, was similar during the two measurement periods. The fast-track area treated nearly twice as many patients. In total, the ED treated almost as many patients a month as the ED in Study I. The number of staff was the same during the two measurement periods.
Across all 56 days of measurements the daily equivalent continuous noise levels $\left(L_{\text {Aeq, } 24 h}\right)$ at the control desk had a median of $56.5 \mathrm{~dB}(\mathrm{~A})$, with $90 \%$ of the $L_{\text {Aeq, } 24 h}$ values exceeding $55.3 \mathrm{~dB}(\mathrm{~A})$ and $10 \%$ exceeding $57.8 \mathrm{~dB}(\mathrm{~A})$. These noise levels resembled those for Centers 2 and 3. Like in Study I, the $L_{\text {Aeq, 24h }}$ values were significantly higher for workdays than weekends, $F(1,54)=5.45, p<0.05$. The median $L_{\text {Aeq, } 24 h}$ values for workdays and weekends were 56.7 and $55.8 \mathrm{~dB}(\mathrm{~A})$, respectively. Contrary to Study I, we did not find lower noise levels for days using the electronic as opposed to dry-erase whiteboard. The effect of whiteboard approached significance, $F(1,54)=3.45, p=0.07$, but in the opposite direction. That is, during the use of electronic whiteboards the daily equivalent continuous noise levels had a median of $56.5 \mathrm{~dB}(\mathrm{~A})$, whereas the median was 56.4 $\mathrm{dB}(\mathrm{A})$ during the use of dry-erase whiteboards.

Table 5 shows equivalent continuous noise levels at the control desk for each shift. There was a significant effect of shift on the $L_{\text {Aeq, } 8 h}$ values, $F(2,165)=271.65, p<0.001$, with Bonferroni-adjusted pairwise comparisons indicating higher $L_{\text {Aeq, } 8 h}$ values for day and evening shifts than for night shifts. Contrary to Study I the $L_{\text {Aeq, } 8 h}$ values for day and evening shifts were not different $(p=0.2)$. Apart from the somewhat higher noise levels for evening shifts the $L_{\text {Aeq, } 8 h}$ values resembled those at Centers 2 and 3 . The maximum noise level measured at the control desk exceeded $83 \mathrm{~dB}(\mathrm{~A})$ during both day and evening shifts. In addition, $5 \%$ of the $L_{\text {Aeq, Is }}$ measurements exceeded $62.4 \mathrm{~dB}(\mathrm{~A})$. That is, 4027 noise measurements, spread across all three shifts, exceeded $62.4 \mathrm{~dB}(\mathrm{~A})$. Unsurprisingly, the minimum $L_{\text {Aeq, } 1 \mathrm{~s}}$ measurement of $34.7 \mathrm{~dB}(\mathrm{~A})$ was obtained at night.

\subsection{Results of Observations}

The control desk was the central information hub of the ED. The coordinating nurse (a role rotating among the nurses) was almost permanently there, the coordinating physician (a role rotating among the senior physicians) was there repeatedly but also saw patients, and a secretary worked there during day shifts. In addition, all physicians and nurses visited the control desk to make themselves available for new assignments, learn which patient to see next, retrieve and orient themselves in patient records, order blood tests and other examinations, obtain the results of these tests and examinations, report the status of their treatment of their patients, seek advice from experienced colleagues, make themselves available for questions, and briefly socialize in between patients. Some of the information exchanged at the control desk was available or

Table 5. Equivalent Continuous Noise Levels in $\mathrm{dB}(\mathrm{A})$ at the Control Desk (Study II)

\begin{tabular}{|c|c|c|c|c|c|c|}
\hline & \multicolumn{3}{|c|}{$L_{A e q, 8 h}, N=168$} & \multicolumn{3}{|c|}{$L_{A e q, 1 s}, N=80556$} \\
\hline & $L_{90}$ & Median & $L_{10}$ & $\boldsymbol{L}_{\min }$ & $L_{05}$ & $\boldsymbol{L}_{\max }$ \\
\hline \multicolumn{7}{|l|}{ Shift } \\
\hline Day (08-16) & 55.6 & 57.7 & 59.8 & 36.9 & 63.3 & 83.3 \\
\hline Evening (16-00) & 55.8 & 57.1 & 58.8 & 37.3 & 62.9 & 83.1 \\
\hline Night (00-08) & 50.7 & 52.3 & 54.4 & 34.7 & 58.7 & 76.7 \\
\hline Total & 51.5 & 56.6 & 58.8 & 34.7 & 62.4 & 83.3 \\
\hline
\end{tabular}


entered on the whiteboard but most visits at the control desk involved oral communication, in particular with the coordinating nurse. The control desk was also the location at which paramedics handed over patients on ambulance stretchers to the ED clinicians, porters arrived with hospital beds to retrieve patients who were being transferred to other departments, staff with blood-test trolleys and portable X-ray equipment got information about the patient room in which they were needed, and patients and their relatives got additional information. All these people, activities, and pieces of equipment generated noise.

Often many people were present at the control desk at the same time, including a situation in which ten people were at the control desk: the coordinating physician was walking through the admitted patients with another physician, the coordinating nurse and another nurse were reprioritizing the patients to free staff for two patients who were about to arrive, three clinicians stood together discussing a patient on the basis of multiple paper forms with information about the examinations of the patient, a secretary was typing information into the electronic patient records, a nurse was reading the information about her new patient and filling in a form to order blood tests for the patient, and a clinician was consulting the whiteboard and updating its information about the patient she had just seen. A minute later seven of the ten clinicians were no longer at the control desk.

In addition to people talking face to face, phone conversations contributed considerably to the noise level because new admissions were announced this way and because the communication with other departments was mainly by phone. The coordinating physician and nurse spent considerable time answering phone calls and handing phones on to the clinicians responsible for the patient in question or otherwise capable of providing the requested information. For example, a relative of a patient called and the phone was picked up by a physician who was in the vicinity of the control desk. He asked the relative to wait and handed the phone to the coordinating nurse who was just finishing another conversation. The coordinating nurse talked briefly with the relative and then asked the relative to wait while she located the nurse caring for the patient. This nurse happened to be passing by the control desk; she picked up the latest papers about the patient from the rack in the control desk and talked with the relative.

The patients contributed only modestly to the noise level at the control desk because they were mostly in the patient rooms. During busy periods all patient rooms were, however, occupied. On such an occasion, a patient discharged to return to his nursing home was lying in a bed that had been wheeled out to the control desk to free the patient room for another patient. Transportation for the patient had been ordered 2.5 hours ago but had not yet arrived. The patient was moaning repeatedly and loudly, in a confused and crying voice. Whereas this situation was hard to do anything about, other situations appeared to present opportunities for lowering the noise level. For example, the coordinating physician on one occasion walked by the control desk with a dictation machine in one hand and some papers about a patient in the other. He was walking around the ED while dictating a new entry in the patient record but was interrupted several times by colleagues and interrupted himself several times to solicit advice to other colleagues who were discussing their patients. On multiple occasions the physician restarted the dictation by stating his name and repeating the first few sentences of the new patient-record entry. This went on for about 10 minutes. On another occasion, a porter arrived to retrieve a patient but did not know which room the patient was in. The information was available on the electronic whiteboard but he did not consult it. Rather, he asked the coordinating nurse. The ED clinicians have, however, commented that after the introduction of the electronic whiteboard porters and bloodtest staff more often consult and update the whiteboard themselves, thereby replacing oral communication with quiet system use.

\subsection{Discussion}

Study II confirms most of the findings from Study I. The median noise level at the control desk was similar to that at the two least noisy centers in Study I and the maximum $L_{\text {Aeq, } 1 s}$ value exceeded $83 \mathrm{~dB}(\mathrm{~A})$, as it did at Centers 1 and 3 . The main difference is that whereas the electronic whiteboards in Study I were accompanied by a lower noise level, there was no reduction in the noise level at the control desk after the introduction of the electronic whiteboard. A likely reason for this difference is that the main noise sources in the EDs - clinicians talking, phones ringing, and equipment being moved around - were only indirectly affected by the whiteboards. Thus, the effect of the electronic whiteboards on the noise level depended on the work practices that became associated with the use of the electronic whiteboards, not on the whiteboards as such. These work-practice changes included that the nurses, but not the physicians, spent more of their time in the patient rooms and less at the control desk [37]. The control desk remained an area where clinicians frequently consulted colleagues for information and advice. Another reason may be that the ED in Study I benefitted more from the electronic whiteboard because this ED was larger and had a physical layout that made it more difficult to maintain an overview. Thus, the whiteboard information might have replaced more oral communication than in Study II where a clinician at the control desk could see who entered and left most patient rooms and might not save much oral communication by getting access to the electronic whiteboard.

\section{CONCLUDING DISCUSSION}

The noise level at the two EDs was similar and in both studies measured for two four-week periods. At the noisiest of the four measurement locations (Center 1) the median day-shift equivalent continuous noise level was $61.6 \mathrm{~dB}(\mathrm{~A})$ and even at the quietest measurement location (Center 2) $90 \%$ of the daily equivalent continuous noise levels were above 53.6. This noise level should be a cause for concern because noise levels above $50 \mathrm{~dB}(\mathrm{~A})$ have repeatedly been found to decrease the performance on cognitive tasks and the intelligibility of human speech [4, 28-30]. Cognitive tasks and human speech are fundamental to ED work, and the negative effects of the noise level adds to an environment that is already stressful due to the frequent need for responding quickly and the constant awareness that errors may cause harm to patients. 
The intervals from $L_{90}$ to $L_{10}$ were less than $7 \mathrm{~dB}(\mathrm{~A})$ wide for day, evening, as well as night shifts. These intervals, which by definition include the noise level of $80 \%$ of the shifts, subsume the noise levels reported in two of the six previous studies of ED noise, whereas three previous studies reported noise levels above these intervals and one below (cf. Table 1). The noise level was roughly $10 \mathrm{~dB}(\mathrm{~A})$ higher in the three studies $[17,18,31]$ that reported noise levels higher than in the EDs we studied, indicating a substantially noisier environment. The $L_{90}-L_{10}$ intervals in Studies I and II were fairly narrow compared to the gap between these intervals and the maximum $L_{\text {Aeq, ls }}$ values. For brief periods of time the noise level was above $80 \mathrm{~dB}(\mathrm{~A})$ at all four measurement locations. At two of the measurement locations noises above $80 \mathrm{~dB}(\mathrm{~A})$ also occurred during night shifts. These maximum noises were considerably above the limits recommended byPhilbin et al. [16] as maximum $L_{\text {Aeq, ls }}$ values.

After the introduction of electronic whiteboards the noise level has decreased at one ED but not at the other. This mixed result was not caused by changes in the number of patients or clinicians from before to after the introduction of the electronic whiteboards. Also, the electronic whiteboard was the same in the two EDs. We contend that the differences in the size and physical layout of the two EDs affected the benefit they derived from the electronic whiteboard in terms of improved overview and, thereby, the extent to which the electronic whiteboard reduced the need for oral communication. This contention is supported by Scupelli et al. [38]. In addition, the organizational implementation of the electronic whiteboards may affect the extent to which the noise reductions they afford were realized by the EDs. In Study II, porters and blood-test staff have, for example, gradually and on their own initiative started updating information on the electronic whiteboard rather than orally informing the coordinating nurse. This change could probably have been achieved quicker and more exhaustively by instructing the staff to adopt this new work practice.

The minimum $L_{\text {Aeq, }, \text { ss }}$ values may roughly approximate the level of background noise. To the extent this is accurate the background noise at the two EDs was within EPA recommendations [13] and only slightly above WHO recommendations [4], suggesting that the target of interventions to reduce the noise level should be the foreground noise rather than the background noise. Because intelligible speech is a dominant noise source in the EDs an important class of interventions should focus on changing clinicians' behavior. By simple means such as moving closer to their conversation partners and stepping away from others when talking on the phone, the clinicians can reduce the need for raising their voices. Also, reading information off the whiteboards, rather than asking the coordinating nurse for it, will contribute to a reduction of the noise level. The negative effects of the noise level may be exacerbated by the high ratio of intelligible speech because intelligible speech is one of the most distracting noise sources [27]. Finally, interventions could target building factors such as open-plan work areas, which allow the noise to travel farther, and the prevalence of hard surfaces that allow for effective cleaning but do not absorb sound.

\section{CONFLICT OF INTEREST}

The author is neither financially, personally, nor otherwise related with Imatis and the healthcare region, apart from the professional relations that have evolved in the course of the project.

\section{ACKNOWLEDGEMENTS}

This study was part of the Clinical Overview project, which is conducted in collaboration with Region Zealand and Imatis. The study was co-funded by Vækstforum Sjælland and Innovasjon Norge. The co-funding sources had no role in the study design, in the collection, analysis, and interpretation of data, or in the writing of this paper. Special thanks are due to the EDs and their staff.

\section{REFERENCES}

[1] Bayo MV, Garcia AM, Garcia A. Noise levels in an urban hospital and workers' subjective responses. Arch Environ Health 1995; 50(3): 247-51.

[2] Falk SA, Woods NF. Hospital noise - Levels and potential health hazards. New Engl J Med 1973; 289(15): 774-81.

[3] Rashid M, Zimring C. A review of the empirical literature on the relationships between indoor environment and stress in health care and office settings. Environ Behav 2008; 40(2): 151-90.

[4] Berglund B, Lindvall T, Schwela DH, Eds. Guidelines for Community Noise. Geneva, CH: World Health Organization 1999.

[5] Dube JAO, Barth MM, Cmiel CA, et al. Environmental noise sources and interventions to minimize them: A tale of 2 hospitals. J Nurs Care Qual 2008; 23(3): 216-24.

[6] Konkani A, Oakley B. Noise in hospital intensive care units - A critical review of a critical topic. J Crit Care 2012; 27(5): 522.e1.e9.

[7] Tijunelis MA, Fitzsullivan E, Henderson SO. Noise in the ED. Am J Emerg Med 2005; 23(3): 332-5.

[8] Aronsky D, Jones I, Lanaghan K, Slovis CM. Supporting patient care in the emergency department with a computerized whiteboard system. J Am Med Inform Assoc 2008; 15(2): 184-94.

[9] Bisantz AM, Pennathur PR, Guarrera TK, et al. Emergency department status boards: A case study in information systems transition. J Cogn Eng Decis Mak 2010; 4(1): 39-68.

[10] Wong HJ, Caesar M, Bandali S, Agnew J, Abrams H. Electronic inpatient whiteboards: Improving multidisciplinary communication and coordination of care. Int J Med Inform 2009; 78(4): 239-47.

[11] France DJ, Levin S, Hemphill R, et al. Emergency physicians' behaviors and workload in the presence of an electronic whiteboard. Int J Med Inform 2005; 74(10): 827-37.

[12] Hertzum M. Electronic emergency-department whiteboards: A study of clinicians' expectations and experiences. Int J Med Inform 2011; 80(9): 618-30.

[13] EPA. Information on levels of environmental noise requisite to protect public health and welfare with an adequate margin of safety. EPA/ONAC 550/9-74-004. Washington, DC: Environmental Protection Agency 1974.

[14] MacKenzie DJ, Galbrun L. Noise levels and noise sources in acute care hospital wards. Build Serv Eng Res Technol 2007; 28(2): 11731.

[15] Pope D. Decibel levels and noise generators on four medical/surgical nursing units. J Clin Nurs 2010; 19(17\&18): 2463-70.

[16] Philbin MK, Robertson A, Hall JW. Recommended permissible noise criteria for occupied, newly constructed or renovated hospital nurseries. J Perinatol 1999; 19(8): 559-63.

[17] Orellana D, Busch-Vishniac IJ, West JE. Noise in the adult emergency department of John Hopkins Hospital. J Acoust Soc Am 2007; 121(4): 1996-9.

[18] Vinodhkumaradithyaa A, Srinivasan M, Ananthalakshmi I, et al. Noise levels in a tertiary care hospital. Noise Health 2008; 10(38): 11-3.

[19] Tsara V, Nena E, Serasli E, Vasileiadis V, Matamis D, Christaki P. Noise levels in Greek hospitals. Noise Health 2008; 10(4): 110-2.

[20] McLaren E, Maxwell-Armstrong C. Noise pollution on an acute surgical ward. Ann Roy Coll Surg Engl 2008; 90(2): 136-9. 
[21] Ratnapalan S, Cieslak P, Mizzi T, McEvoy J, Mounstephen W. Physicians' perceptions of background noise in a pediatric emergency department. Pediatr Emerg Care 2011; 27(9): 826-33.

[22] Morrison WE, Haas EC, Shaffner DH, Garrett ES, Fackler JC. Noise, stress, and annoyance in a pediatric intensive care unit. Crit Care Med 2003; 31(1): 113-9.

[23] Topf M, Dillon E. Noise-induced stress as a predictor of burnout in critical care nurses. Heart Lung 1988; 17(5): 567-74.

[24] Parthasarathy S, Tobin MJ. Sleep in the intensive care unit. In: Pinsky MR, Brochard L, Mancebo J, Hedenstierna G, Eds. Applied Physiology in Intensice Care Medicine. $2^{\text {nd }}$ ed. Dordrecht: Springer 2009; pp. 191-200.

[25] Simpson T, Lee ER, Cameron C. Relationships among sleep dimensions and factors that impair sleep after cardiac surgery. Res Nurs Health 1996; 19(3): 213-23.

[26] Healey AN, Primus CP, Koutantji M. Quantifying distraction and interruption in urological surgery. Qual Saf Health Care 2007; 16(2): 135-9.

[27] Sundstrom E, Town JP, Rice RW, Osborn DP, Brill M. Office noise, satisfaction, and performance. Environ Behav 1994; 29(2): 195-222.

[28] Venetjoki N, Kaarlela-Tuomaala A, Keskinen E, Hongisto V. The effect of speech and speech intelligibility on task performance. Ergonomics 2006; 49(11): 1068-91.

[29] Nagar D, Pandey J. Affect and performance on cognitive task as a function of crowding and noise. J Appl Soc Psychol 1987; 17(2): $147-57$.
[30] Jahncke H, Hygge S, Halin N, Green AM, Dimberg K. Open-plan office noise: Cognitive performance and restoration. J Environ Psychol 2011; 31(4): 373-82.

[31] Buelow M. Noise level measurements in four Phoenix emergency departments. J Emerg Nurs 2001; 27(1): 23-6.

[32] Short AE, Short KT, Holdgate A, Ahern N, Morris J. Noise levels in an Australian emergency department. Australas Emerg Nurs J 2011; 14(1): 26-31.

[33] Zun LS, Downey L. The effect of noise in the emergency department. Acad Emerg Med 2005; 12(7): 663-6.

[34] Rasmussen R. Electronic whiteboards in emergency medicine: A systematic review. In: Proceedings of the IHI2012 International Health Informatics Symposium. New York: ACM Press 2012; pp. 483-92.

[35] IEC 61672. Electroacoustics - Sound level meters. Part 1: Specifications. Geneva, CH: Int Electrotech Commision 2002.

[36] Rosenthal R, Rosnow RL. Essentials of behavioral research: Methods and data analysis. $2^{\text {nd }}$ ed. Boston, MA: McGraw-Hill 1991.

[37] Hertzum M, Simonsen J. Work-practice changes associated with an electronic emergency department whiteboard. Health Inform J 2013; 19(1): 46-60.

[38] Scupelli P, Xiao Y, Fussell SR, Kiesler S, Gross MD. Supporting coordination in surgical suites: Physical aspects of common information spaces. In: Proceedings of the CHI 2010 conference on human factors in computing systems. New York: ACM Press 2010; pp. $1777-86$

(C) Morten Hertzum; Licensee Bentham Open.

This is an open access article licensed under the terms of the Creative Commons Attribution Non-Commercial License (http://creativecommons.org/licenses/by$\mathrm{nc} / 3.0 /$ ) which permits unrestricted, non-commercial use, distribution and reproduction in any medium, provided the work is properly cited. 